\title{
Reconhecer a morte
}

\section{Christophe Bident ${ }^{1}$}

"Maurice Blanchot morreu". Este enunciado, tão seco e lapidário quanto aberto e vertiginoso, só posso formulá-lo hoje como uma citação. Uma autocitação, pois é a frase com a qual abri o colóquio que Pierre Vilar e eu organizamos, há quase dois anos, apenas trinta e quatro dias decorridos do desaparecimento de Blanchot. Uma citação também num nível secundário, já que foi com a mesma frase, retomando a minha e questionando o emprego que eu havia feito, que Jacques Derrida iniciou sua própria intervenção no mesmo colóquio, três dias mais tarde. Tratava-se de mais um texto de Derrida sobre Blanchot: seguiu com exatidão as palavras pronunciadas por ocasião dos obséquios deste último. Uma intervenção a mais, sim, mas que seria a última: a última, tal é, aliás, um pouco simbolicamente, o lugar que ela ocupa na última versão de Parages (Paragens) lançada enquanto o seu autor ainda vivia. Já que, desde então, tivemos que pronunciar um outro enunciado, tão sonoro quanto o primeiro: "Jacques Derrida morreu". Desde então, escrevi algumas páginas com o objetivo de homenageá-lo e em sua memória. No lugar de cicatrizes, "cicatrizes para Jacques Derrida".

Situo estas duas frases: "Maurice Blanchot morreu", "Jacques Derrida morreu", e não cesso de dizer "também". "Também" dimensiona mal, em termos de igualdade e como suplemento, a lembrança que temos e manifestamos dos mortos. Uma medida desajeitada, embaraçosa, que interroga no entanto nossa postura: nossa memória, nossa palavra, nossa vaidade, nossa inquietação, nosso abandono, nosso dever, nosso desconhecimento, nosso reconhecimento. $O$ que acentua nosso questionamento é que Maurice Blanchot e Jacques Derrida não cessaram de dizer "também", não cessaram, eles próprios, de escrever textos para os mortos. E estes textos para os mortos eram talvez "também" textos sobre

1 Traduçăo de Maria José Werner Salles, revista por Sérgio Medeiros 
suas próprias mortes. Isso convocava uma escrita reflexiva, infinitamente reflexiva, em Blanchot, em Derrida, e de Derrida com respeito_à Blanchot. Gostaria de considerar, com vocês, hoje, um exemplo. Trata-se de um texto de Thomas L'Obscur (Thomas o obscuro), no qual Thomas, para dizê-lo rapidamente, cava em vão sua própria tumba. É uma passagem que Maurice Blanchot reproduz sem quase nenhuma mudança, da primeira à segunda versão do livro, e que Jacques Derrida retoma no seu último texto sobre Maurice Blanchot. Leiamo-no, releiamo-no, na ediçāo de 1950:

"De joelhos, com as costas curvadas, Thomas cavava a terra. Ao seu redor, estendiam-se algumas covas ao longo das quais o dia mantinha-se rechaçado. Pela sétima vez, ele preparava lentamente, deixando no solo a marca de suas mãos, um grande buraco que ampliava para o seu tamanho. E enquanto que ele cavava, o vazio, como se tivesse sido preenchido por uma dúzia de mãos, após por braços, enfim pelo corpo todo inteiro, oferecia por sua vez uma resistência que logo ele não poderia vencer. A tumba estava plena de um ser do qual ela absorvia a ausência. Um cadáver desalojado aí enterrava-se, encontrando nesta ausência de forma, a forma perfeita de sua presença. Era um drama cujo horror era experimentado, durante o sono, pelos homens do vilarejo. Assim que, a tumba foi concluída, Thomas nela jogou-se, tendo fixado no seu pescoço uma grande pedra, ele se chocou com um corpo mil vezes mais duro do que o solo, o corpo mesmo do coveiro que já havia entrado na cova para cavá-la. Esta cova que tinha exatamente o seu tamanho, sua forma, sua largura, era como seu próprio cadáver, e a cada vez que ele tentava aí enterrar-se, assemelhava-se a uma morte absurda que teria tentado enterrar o seu corpo no seu corpo. Havia doravante, em todas as sepulturas nas quais ele poderia ter tomado lugar, em todos os sentimentos que são também tumbas para os mortos, neste aniquilamento pelo qual ele morria sem permitir que se acreditasse morto, havia um outro morto que o tinha precedido e que the era idêntico, impelia até o extremo a ambiguiidade da morte e da vida de Thomas".

O que está acontecendo? Thomas, o duplo, o gêmeo, o obscuro ou incrédulo, parece a vítima de um suplício infinito: condenado a cavar sua própria tumba, que é preenchida assim que ele tenta nela se jogar, ele encontra-se "na própria morte, privado da morte" - é a fórmula da página seguinte -, assim já "impedido de morrer pela própria morte" - é ela, publicada meio século mais tarde, neste texto tão longamente, pacientemente e justamente iniciado por Blanchot, $O$ Instante da minha morte. Nesta cena da escavação da tumba, que poderia já intitular-se um instante, ou antes, uma instância da morte infinitamente repetida, Thomas afronta uma "resistência" tão inconsciente quanto inominável e invencível. Ele opõe-se primeiramente a "dúzias de mãos", em seguida a "braços", em seguida ao "corpo todo inteiro". Quais são estas "dúzias de mãos"? Elas lhe são tangíveis, elas que nos são igualmente visíveis? Quais são estes braços? Faz-se necessário imaginá-los, eles também em dúzias, como suportes destas mãos? E porquanto "o corpo todo inteiro" aparece subitamente, sublimando seus estados fragmentados? Trata-se do mesmo corpo, do corpo das mesmas mãos e dos mesmos braços, quer dizer, um corpo monstruoso ou fantástico que surgiria das entranhas da terra? Ou trata-se já da redução que se anuncia, aquela de "ser" consistente, mas ausente, aquela de um "cadáver" sem forma mas "encontrando nesta ausência de forma a forma perfeita de sua presença", aquela de um "corpo mil vezes mais duro do que o solo"? Esta redução nos reconduz a Thomas: este corpo na tumba, é já o seu, o mesmo, "o corpo mesmo", "o corpo do coveiro"? Ou é apenas a sua imagem, a imagem de "seu próprio cadáver", uma 
imagem de uma perfeita exatidão, feita de "seu tamanho, sua forma, sua espessura", de uma perfeita exatidáo e de uma crueldade absoluta, uma pura miragem que faz aparecer e desaparecer à vontade na cova o corpo de Thomas? Ou trata-se da forma de um puro fantasma, uma representação alterada de Thomas, "um outro morto", "outro" mas " que lhe é idêntico", ou ainda, uma percepção impessoal, uma percepção pelo absurdo, impulsionando "até a extrema ambigüidade" não de sua morte ou de sua vida, mas "a ambigüidade da morte e da vida de Thomas"?

Retiro com certeza arbitrariamente esta passagem da narrativa como do romance na qual se encontra, cada vez, inserida num conjunto no qual a continuidade de superfície mantém como um sintoma a heterogeneidade das representações, que representa uma espécie de loucura do dia. Esse desligamento em forma de distanciamento, eu o reivindicarei, todavia, como uma operação provisória destinada a fazer reconhecer a aposta possivel destas linhas, sem fazê-las perder seus "procedimentos estranhos". Pode-se assim interrogar-se sobre suas incoerências incoerentes, suas unidades complexas, suas autonomias fabricadas à força de superposições. Assim vão a narração, que balança entre visão externa, o tratamento do tempo, que gira entre singulativo, iterativo e durativo, a sintaxe e a fluidez harmoniosa, subitamente quebrada no limite do anacoluto. Assim vai a cena, que descreve a realidade de um trabalho material (é a posição do corpo, é a impressão das mãos), até a identidade vertiginosa entre os continentes e os conteúdos (fossa, buraco, vazio, tumba, sepultura/corpo, ser, cadáver), até a indistinção dos elementos sólidos e líquidos (a água na qual se joga no momento em que prende uma pedra ao redor do pescoço, transforma-se, aqui, em "um corpo mil vezes mais duro do que o solo"). A descrição impõe a este trabalho elementar a metáfora exatamente material de um trabalho psíquico (o dia está "rechaçado" ao redor das tumbas, o vazio oferece uma "resistência" ao "trabalho" de Thomas, em luta com suas próprias representações imaginárias). 0 discurso quebra assim a continuidade de uma descrição com traços e movimentos puramente denotativos, realçando-os, cada qual por sua vez, e contraditoriamente, numa dimensão alegórica, num estilo fantástico, com uma voz mística, numa reflexão teológica ou ateológica. A alegoria é a exclusividade dos grandes números: sete, doze, mil; o fantástico são as imagens, assim aquela do duplo como morte, esta "palavra absurda que teria tentado enterrar seu corpo no seu corpo"; a voz mística é o retorno das grandes opressões paradoxais, "encontrando nesta ausência de forma, a forma perfeita de sua presença"; o pensamento teológico, a evocação de uma presença real, e o pensamento ateológico, as formulações da "ambigüidade da morte e da vida de Thomas", que anuncia o que Blanchot, três páginas adiante, no final do capítulo, nomeará a ressurreição não do morto, mas da morte, ou ainda "este aniquilamento pelo qual ele morria sem permitir que se o acreditasse morto", prefiguração longínqua do morrer. A cena toma assim valor de exemplo: a última frase do trecho garante a diferença irreversível marcada pelo acontecimento ("havia portanto doravante"), da qual ela firma a significação abstrata: "todas as sepulturas" conotam "todos os sentimentos", "tantas tumbas para os mortos". Os destinatários deste exemplo são citados: são "os homens do vilarejo", assombrados até nos seus sonos pela cena, a tal ponto que nenhum deles, começando ao menos por eles, não pode deixar Thomas como morto.

$\mathrm{O}$ que estou fazendo aqui, portanto, é olhar, rapidamente, como se organiza uma passagem ao mesmo tempo extremamente sensível e complicada. Partamos de uma primeira estranheza. Neste trecho, Thomas tem bem um corpo, um tamanho, 
uma espessura, mãos, joelhos, costas, pescoço... mas parece não ter rosto. Ele escava, penetra, joga-se, choca-se... toca, mas não vê. Não irei sugerir deste modo a imagem de um homem cego ou sem rosto... nem Édipo, nem Acéfalo. Antes talvez a imagem de uma pantomima, de uma pantomima mascarada, de uma pantomima que disfarça o rosto cobrindo-se com um tecido, como Étienne Decroux, na mesma época na qual Blanchot escrevia Thomas l'Obscur, praticava-o. Escrita para um torso e membros, a cena pode ser lida como um esboço de pantomima ou de dança, sem rosto nem palavras. Ela chama o silêncio e a obsessão: ela só se transmite no sono vigilante dos "homens do vilarejo". Um silêncio assombrado pelos mortos, por estes mortos que não morrem, ou pela morte que não morre, por este parceiro invisível da existência. Parceiro invisível? Conhece-se bem sobre a metáfora de Blanchot, a leitura como "uma dança com um parceiro invisivel num espaço separado, uma dança alegre, desvairada, com o 'túmulo' ". Conhece-se menos, entre nós, aquela de Mary Wigman, a coreógrafa alemã, que sempre concebeu o solo como uma dança "com um parceiro invisivel", "um parceiro invisível", mas "perfeitamente presente na minha imaginação", segundo a sua precisão: uma forma de presença real, de presença real da morte. Já que para dar um exemplo desta presença, Mary Wigman remete às pesquisas que ela efetuou para uma criação que se tornaria a terceira dança, A Chamada da Morte (Todesruf), de um ciclo de seis solos, Sacrificio (Opfer). Leio alguns trechos desta passagem no seu livro A Linguagem da Dança:

"Desde o início, havia algo - o sentimento de ser chamada que vinha de longe, emergindo de uma profunda obscuridade e de uma pesada exigência. Isso forçava o meu olhar a descer novamente e voltar-se na direção das profundezas, e meus braços a estender-se como uma barreira, como para repelir uma poderosa investida. Eu queria precipitar-me à frente, jogar-me contra esta força! Mas logo nos primeiros passos, tive que parar, como transpassada (...) havia lá um pólo oposto, um ponto no espaço, imobilizando o olhar e o pé. Esta tensāo criada sem dúvida em mim mesma e refletida no espaço, forçava todavia meu corpo a se voltar bruscamente e arqueava as minhas costas distante para trás, os braços novamente afastados, impotente e desesperada. Agora esta forma estava acima de mim, dilatava-se como uma sombra imensa que não me deixaria escapar. Mas absolutamente nada mais de fraqueza! Já que eu não queria de modo algum escapar, mas ao contrário, penetrá-la. Eu queria compreender, abraçar, conhecer. (...) Pergunta, resposta! Todas as duas enunciavam-se simultaneamente em mim. Eu era 'aquela que chama' e 'a chamada' simultaneamente. Num certo momento da dança comecei a tremer. E eu soube repentinamente: a Morte está falando contigo. Não a minha morte, nem a de outra pessoa. Antes como se uma lei da vida quisesse se impor, uma ordem que eu não havia recebido até aquele momento. E eu tive uma primeira intuição de tudo o que está escondido atrás da vida, dando-me conta pela primeira vez de todos os irrevogáveis, de toda finalidade e extinção. $\mathrm{E}$ foi assim que terminei a dança, na aceitação consciente e o reconhecimento desta grande lei que nos domina a todos e que denominamos morte".

Não procuro sobrepor o texto de Blanchot e o de Wigman, a ilustrá-los um pelo outro. Uma série de diferenças notórias percebe-se com a simples leitura. Porém em 1931, ano precedente ao trabalho de Tbomas L'Obscur (Thomas o obscuro), Mary Wigman revela como manifestação secreta e necessária da nova criação cinematográfica, a chamada obscura de uma voz irrevogável, a luta interiorizada com uma força gêmea: a morte impessoal. 0 dorso arqueado "distante para trás" forma este arco que uma 
outra coreógrafa, Doris Humphrey, o reconhecerá como o teor mesmo da dança: entre duas posições imóveis, "o corpo em pé sem movimento no qual milhares de ajustes necessários para mantê-lo em pé são invisíveis, e o horizontal, a imobilidade final", a vida e a dança "formam este arco entre duas mortes".

Assim alguma coisa não morre na morte e apela para ser transmitida. Alguma coisa não morre na morte que nos permite não morrer nós mesmos. Alguma coisa ressuscita não apenas do morto, mas da morte. É como a lei das extrapolações de Blanchot: "Os mortos ressuscitavam morrendo", leremos ainda em L'Attente L'Oubli (A Espera o esquecimento). O que vem dos mortos constitui apenas a morte deles, ou antes, seu morrer. É ao mesmo tempo um "drama", horrivel, enfatiza Thomas L'Obscur (Thomas o obscuro), e uma "dança alegre", acentua O Espaço Literário. É o drama de nosso sono e a dança de nossa leitura. $O$ drama do vilarejo e a dança da comunidade, um e outro virtualmente reunidos em torno do túmulo.

Retorno a Jacques Derrida, as três tomadas de palavra de Jacques Derrida. Sobre os dezesseis textos reunidos em Chaque Fois Unique (Cada vez único), o fim do mundo, três foram pronunciados "com o túmulo", em pé, num porte dificil e não obstante ajustado, ao lado de corpos entregues a sua "imobilidade final": aqueles de Althusser, de Levinas e de Blanchot. No texto consagrado a Althusser, leio este parêntese: "somos só nós mesmos a partir deste lugar de ressonância em nós do outro, e do outro mortal". Assim só seríamos nós mesmos no drama de nosso sono e a dança de nossa leitura. Na ressurreição não do morto, mas da morte. É o que deixa entender Jean-Luc Nancy na sua leitura desconstrutora, ou antes, na leitura da veia autodesconstrutora da cena evangélica do Noli me tangere: Jesus só pronuncia estas palavras para partir, sua presença gloriosa só está de acordo com sua retirada, e "o que para a religião é o recomeço de uma presença, sustentando a garantia fantasmagórica de uma imortalidade, revela-se aqui não ser outra coisa além da partida na qual a presença eleva-se verdadeiramente, trazendo o seu sentido, segundo esta partida. A ressurreição da morte é intocável, ela só se dá como cena sob a imagem de um eclipse, e já que a ressurreição do morto oferece apenas uma parte do acontecimento, a presença sem a partida, a revelação sem a ausência, tocar no morto acusa a vaidade do desejar apreender da fé. Será no evangelho de João, a fraqueza de Thomas.

Logo, esta diferença entre a ressurreição do morto e a ressurreição da morte, formulada por Blanchot sobre Thomas, "somente Lázaro verdadeiro, cuja morte mesma fora ressuscitada", é precisamente Nancy quem a revelou, num texto pronunciado no ano passado, na abertura de um ciclo de conferências, organizado junto a uma oficina de escrita de leitura de Pierre-Antoine Villemaine, na Biblioteca Pública de Informação de Beaubourg. Nancy prolongava desta forma suas análises de Noli me tangere, observando que a ressurreição da morte abre "um espaço fora do sentido" e "subtrai à morte da mortalidade o morrer da imortalidade pelo qual incessantemente eu conheço esta retirada radical do sentido, e, portanto, a verdade mesma". Verdade, ele destacava, da literatura: "a literatura suporta a cessação ou a dissipação do sentido", o que escapa à "ontoteologia filosófica", à sua dimensão metafísica: "As práticas metafísicas designam sempre assim um à frente, o futuro de um renascimento, uma maneira de possível e de poder, enquanto que a literatura só escreve o presente do que nos acontece sempre, ou seja, o impossível no qual ser consiste em desaparecer".

Se Thomas coloca-se assim a andar, no final do capítulo cinco de Thomas 


\section{outraTravessia}

L'Obscur (Thomas o obscuro), não é exatamente no sentido romanesco de uma elevação gloriosa, de uma anastasis (ressurreição). "Só Lázaro verdadeiro" é ainda só Thomas verdadeiro, mais verdadeiro, mais suscetivel de verdade do que o Thomas do evangelho, já que a sua elevação procede de uma certeza: erguendo-se de seu túmulo, "ele aparecia sobre a porta estreita de seu sepulcro, não ressuscitado, mas morto e tendo a certeza de ser arrancado ao mesmo tempo da morte e da vida". Só Thomas verdadeiro, gêmeo do Cristo na abstração de uma forma neutra, nem morta nem viva após ter sido viva e após morta, uma forma na qual ressuscita assim não o morto, mas a morte, cuja imagem se condensa na constituição de uma "figura ausente" com um "rosto sorridente e vivo".

A ressurreição da morte nesta forma neutra, eis aí, se ouso dizer, que se oferece esquivando-se a todo reconhecimento, sem o qual "nós não somos jamais nós mesmos".

Mas se a dançarina for ao mesmo tempo "aquela que chama" e "a chamada"? Se Thomas estiver ao mesmo tempo no túmulo e fora do túmulo? Se, só Thomas verdadeiro, for ao mesmo tempo Jesus e Thomas? Se for impossível de ser ele próprio sem imaginar de se olhar morto? É o movimento que retém, por exemplo, Blanchot nas páginas de Michel Leiris, em torno do sonho angustiado de Nuits sans Nuits (Noites sem noites) no qual o poeta introduz sua cabeça numa espécie de clarabóia dando sobre um "espaço emparedado", surpreso "na sua obscuridade interior": de fato, conclui Leiris, "é a mim mesmo que olho". Este sonho, Blanchot só pode nele ver um "verdadeiro olhar de além túmulo", de onde ele deduz a lei da narrativa autobiográfica: "A Idade do homem é este olhar lúcido pelo qual o Eu, penetrando sua 'obscuridade interior', descobre o que nele olha, não é mais o Eu, 'estrutura do mundo', mas já a estátua monumental, sem olhar, sem rosto e sem nome: o Ele da morte soberana”. Um pronome sobre cada ombro, de algum modo por assim dizer, como formula Blanchot sobre Thomas, no capítulo da leitura no quarto, que precede imediatamente o capítulo do túmulo. Numa mistura de prazer e de medo, poder-se-ia dizer ainda, de horror e de alegria, Thomas encontra-se observado pelas palavras que ele observa e já "tomado, amassado por mãos inteligiveis", absorto "com seu corpo vivo nas formas anônimas das palavras, dando-lhes a sua substância, formando suas relações, oferecendo à palavra ser seu ser". "Ele estava inerte, fascinado e descoberto. E mesmo mais tarde, assim que, abandonando-se e olhando seu livro, ele se reconheceu com desgosto sob a forma do texto que lia, guardou seu pensamento na sua pessoa já privada de sentido, ao passo que enquanto, empoleiradas nos seus ombros, a palavra Ele e a palavra Eu começavam sua matança, permaneciam palavras obscuras, almas desencarnadas e anjos das palavras, que profundamente o exploravam". Assim, por cima da cabeça de Thomas, forma-se um novo arco entre duas palavras, entre duas mortes.

Assim eu me olho, numa reflexão dividida pela morte, teatro de "palavras obscuras, almas desencarnadas e anjos das palavras", escultura e sepultura da lembrança, "estátua monumental, sem rosto e sem nome". Eu me olho ou a morte me olha, a morte sem olhar me olha (noutro lugar, Blanchot alegará que um "canto de parede" pode tão bem me olhar quanto um rosto"), a morte me olha e não a minha morte, ou a morte em mim, que apesar de mim e através de mim conhecerá a ressurreição. Cena inversa daquela da "semelhança cadavérica", no Espaço Literário, enquanto vivo, olho o cadáver do defunto que "começa a assemelhar-se consigo mesmo", segundo "esta semelhança última que só pode vir de sua morte", conforme dirá Deleuze, por ocasião da morte de 


\section{Itha de Santa Catarina}

Foucault, uma semelhança ao mesmo tempo inquieta e evidente, a de um desenho de máscara, de duplo ou de substituto. Olho a morte, a morte me olha: cenas inversas mas reversíveis e, portanto, imediatamente complementares. As duas imagens se respondem, mantêm-se e sustentam-se. "Viver um acontecimento em imagem", escreve Blanchot, o que é bem o caso da leitura e do luto, "não é ter deste acontecimento uma imagem, nem lhe dar a gratuidade do imaginário". É, portanto, acomodar realmente este acontecimento que não é o lugar de nenhuma metáfora. "O que acontece, prende-nos", continua Blanchot, "como nos prenderia a imagem, isto é, desfaria de nós, dele e de nós, mantendo-nos fora, faz deste fora uma presença onde "Eu" não "se" reconhece. É esta ausência de reconhecimento, ou o reconhecimento na ausência, que faz a intensidade inoxidável do acontecimento.

Estátua, pantomima sem rosto, máscara, substituto, arco entre dois mortos, parceiro invisível, sepultura, túmulo, as imagens acumulam-se e não acabarão. Pensa-se ainda nas moldagens, do Arrêt de Mort (Sentença de morte) a Une Voix Venue d'Ailleurs (Uma voz vinda de outro lugar), aos bustos do artigo sobre Malraux ("os busstos reúnem-se porque o tempo estraçalhou suas cabeças", escreve Blanchot), nestas narrativas e nestes ensaios sempre paradoxais, onde a semelhança consigo mesmo no desaparecimento só se adquire ao preço de uma luta incrível entre vida orgânica e mineração, acaso e necessidade, consternação e dispersão. Remeto para isso ao muito belo artigo de Georges Didi-Huberman, "De ressemblance à ressemblance" ("De semelhança a semelhança"), já que, ao contrário de certo modo de minha reflexão, é aqui uma teoria da imagem que está primeiramente em questão. Didi-Huberman apóia-se em textos de Blanchot para opor aos discursos sobre a imagem-forma ou imagem-síntese, de uma semelhança que reúne, uma teoria da imagem-meio ou da imagem-despojos, de uma semelhança que desune. "A semelhança desune: ela cria a relação, mas não a unidade. Ela cria a relação para melhor atormentar-se. Ela divide o ser. Ela impóe o desvio no momento mesmo em que ela propóe o contato". Curiosamente, reencontra-se aqui o gesto do noli me tangere: desvio mesmo do contato, divisão no tempo mesmo da ascensão, desconhecimento no coração do reconhecimento. Eu digo: "curiosamente", já que 0 artigo abre precisamente um debate com um livro de Nancy, que acabara então de ser lançado, $A u$ fond des images (No fundo das imagens), sobre a interpretação do pensamento heideggeriano da imagem, ele mesmo motivado pela reflexão sobre a fotografia de uma máscara mortuária. Não entrarei aqui neste debate, que vê Nancy afirmar a "dessemelhança" como condição da "semelhança" e da "reunião" de toda imagem, fundamentando-se numa compreensão do Dasein, como o que "não está justamente aqui, mas sempre em outro lugar, no aberto", enquanto que Didi-Huberman remete ao artigo de Emmanuel Levinas, segundo o qual a estética de Blanchot teria como efeito radical desenraizar a ontologia heideggeriana. No lugar em que Nancy escreve "arrancamento do ser ao ser" e continua a ler "a unidade do diverso na imagem", fosse "uma unidade por falta (ausência), uma unidade cega", Didi-Huberman propõe uma "divisão do ser" pelo poder neutro do fundo de toda imagem. Assim, de um lado, "o um da imagem só se mantém no esboço, o pré-traçado e a pré-clarividência de si próprio", "é em suma um imaginando jamais imaginado", ele "provém da morte como o olhar não visivel com respeito ao meu próprio olhar mergulhando na sua imagem colhida", e "isso quer dizer que 'um' vem do outro, pelo outro e na qualidade do 'outro', e não um si mesmo autointuitivo, que vem do outro, pelo outro e na qualidade de outro, para voltar ao outro”, 
eu acrescentaria, isso quer dizer que sem esta imaginação, nós não seríamos 'jamais nós mesmos'. De outro lado, a imagem fixa uma tensão neutra e exatamente essencial: ela "tira sua necessidade desta 'neutralidade' mesmo: nem o único (o único ontológico do ser reunido em si mesmo), nem qualquer coisa (a vaidade das aparências na qual o ser se dispersa completamente)". Assim, segundo Didi-Huberman, "a imagem não é o outro do neutro". Antes seu abrigo, sua caverna, "no meio da coisa e do nada".

Prosseguirei por este aspecto de caverna, outra versão e como pré-histórica do "túmulo". A imagem real, o acontecimento da imagem real advém assim como abrigo da ressurreição, esta ressurreição sem a qual "não somos nunca nós mesmos". Recordo também que é por duas imagens similares, aquelas de porão e de gruta, que Blanchot introduz em Tbomas L'Obscur (Thomas o obscuro) suas propostas de contraponto ao cogito de Descartes. Trata-se, primeiramente, do capítulo dois, no qual Thomas, comprimido por "mil mãos que eram as suas próprias mãos", encontra-se agarrado na noite exígua da "cova arqueada", uma noite "mais terrível que qualquer outra noite, como se ela tivesse realmente saído de uma ferida do pensamento que não se pensava mais, do pensamento tomado ironicamente como objeto por outra coisa além do pensamento" - um pensamento que, "retomado o seu lugar nele, trocava contatos com o vazio". Em seguida, quase noutro extremo da narraçāo, assim medido entre duas cavernas, segue 0 longo capítulo que poderíamos qualificar como prosopopéia de Thomas: "É então que no seio de uma gruta profunda a loucura do pensador taciturno apareceu-me, e palavras ininteligiveis ressoaram nos meus ouvidos, enquanto eu escrevia na parede estas doces palavras: "Eu penso, portanto não sou". "Estas palavras me causaram uma visão deliciosa". É esta "visão deliciosa" para a "loucura do pensador taciturno" que Kevin Hart, num livro recente sobre Blanchot, qualifica de olhar sombrio, ou olho obscuro, The Dark Gaze (O olhar sombrio). Traduzo uma passagem de seu comentário: "não apenas o pensamento não apreende a existência, mas compreende que esta consciência pode se manter sem referências para uma presença viva". Eu acrescentaria: esta consciência só pode se manter em referência a uma presença morta, morta, ressuscitando agonizante. É neste sentido, aliás, que Thomas glosa sua própria fórmula, na página seguinte da narração: "Eu penso: aqui onde o pensamento une-se a mim, eu, eu posso me subtrair do ser, sem diminuição, nem mudança, por uma metamorfose que me conserve comigo mesmo fora de toda cova onde me agarrar. É a propriedade de meu pensamento, não de me garantir a existência, como todas as coisas, como a pedra, mas de me assegurar do ser no nada mesmo e de me engajar a não ser para sentir então minha admirável ausência. Eu penso, diz Thomas, e este Thomas invisível, inexprimível, inexistente que me tornei, fez que doravante eu não estivesse jamais aqui onde eu estava, e não houvesse mesmo nisso nada de misterioso". Eu não estou, eu só estou pela minha ausência, "minha admirável ausência", minha metamorfose "que me conserva comigo mesmo" no coração mesmo de minha ausência.

Minha ausência é, portanto, esta caverna, na verdade este entre-duas-covas ou este arco entre duas covas da ressurreição. Ora, é precisamente por aí, que DidiHuberman, no seu último livro escrito em homenagem a Pierre Fédida, Gestes d'air et de pierre (Gestos de ar e de pedra), retoma sobre a noção de imagem, opondo desta vez, na linhagem de Fédida, a imagem-sopro e a imagem-pedra, complementaridade sobre a qual ele havia já se detido no seu artigo sobre Blanchot, a propósito da morte de J. em L'Arrêt de Mort (Sentença de morte): "o corpo se petrifica como o gesso", comentava, 
"a vida dispersa-se como areia, a imagem mantém-se entre estes dois estados contraditórios". Do artigo ao livro, Didi-Huberman reproduz, aliás, a mesma imagem, aquela de uma ou de diversas Aurai do monumento das Nereidas de Xanthos.

Se estes gestos narrativos ou esculturais, estes gestos de ar e de pedra, de areia dispersa e de corpo rígido, completam-se, é, escreve Didi-Huberman, "para que seja sonhada e despertada, tudo ao mesmo tempo, para que seja velada a memória de um morto". Escrever, sonhar, velar, esculpir, é de fato, segundo Pierre Fédida, fazer "obra de sepultura", noção que não visa nada menos, comenta Didi-Huberman, "que uma reformulação meta-psicológica da noção de ancestralidade". Poder-se-ia aproximar este "ancestral" de "o imemorial" caro a Blanchot, Blanchot que Fédida citou freqüentemente e com o qual dividia a leitura de Mallarmé, Rilke, Celan ou Du Bouchet. Mas retorno aqui ao sono dos "homens do vilarejo" assombrados pelo "drama" de Thomas. Pois o sonho, escreve Fédida após Heráclito, tem este poder de "tocar no morto". "O acontecimento da noite não é o de ter assistido a um sonho. Não é talvez nem mesmo o de ter sonhado ou o de ter vivido um sonho. $\mathrm{O}$ acontecimento da noite é o de ter entrado em contato com o morto". Fédida irá até esta formulação paradoxal e inteiramente blanchotiana, e derridiana, de um sonhar sem o sonho: "O que torna, pelo sonhar, o sonho impossível?", questiona-se. Uma memória positiva do morto não é suficiente à "obra de sepultura" que sua morte nos solicita: faz-se aí necessária uma memória negativa, uma "memória disfarçada, dissimulada", uma memória de tonalidades e de simulações, para contornar o risco incorrido por cada um de se enclausurar no vazio, de tanto pronunciar, eu cito sempre Fédida, uma "sentença de morte sobre o morto". Far-se-ia necessário reler todo o trabalho de Fédida sobre a ausência, sua paixão pela imagem indistinta e espectral, a imagem soprada, a imagem neutra, a imagem, poder-se-ia dizer, nos limites da simples extinção. Eu gostaria, apenas rapidamente, de descrevê-lo assim: é um trabalho que se mantém constantemente sobre o cume da imagem, entre o vazio constitutivo da singularidade psíquica e a morte sempre pensada como um excedente. Um trabalho que segue de perto as capacidades da relação ou da criação meta-psicológica para formar um arco entre este vazio e esta morte, conjuração de uma ausência necessária para fundar um tempo próprio para o sujeito, uma narração economizando a representação de sua própria morte. Um arco sem o qual não seríamos "jamais nós mesmos".

Gostaria também de avaliar, mas não tenho tempo, este pensamento, fazendo-o dialogar com o de Louis Marin, e com o que o próprio Derrida fala em sua homenagem, sobre a subtração da imagem à autoridade do pensamento ontológico, sobre o ser-para-morte da imagem que apenas permite ver a partir de sua instituição desde a morte, sobre a impossibilidade de ser si mesmo sem o olhar antecipado de uma morte impossivel para interiorizar definitivamente. Eu gostaria de avaliar estes pensamentos no espaço intelectual que uma escrita como a de Thomas l'obscur (Thomas o obscuro) contribuiu a abrir. Mas o que me importa hoje, no tempo limitado que é o nosso, é ao menos apreender uma tal exatidão de palavras estéticas, psicanalíticas, filosóficas, é rememorar suas próprias economias numa "memória dissimulada", e de voltar à poética que instala uma vertigem espantosa.

Eis aqui, portanto, ainda, uma cena de reconhecimento, e, ainda uma vez, em Blanchot, uma cena de reconhecimento que resiste a toda análise fundamentada numa fenomenologia narrativa. Como reconhecer de fato o que escapa ao dado, ao posto, ao limitado, ao possível e por um tempo ao menos ao "existenciável"? A virtualidade da 
representação da cena toma sua realidade efetiva no regime romanesco que persiste em encadear os signos impossíveis da duplicidade, da ambigüidade ou da neutralidade. A heterogeneidade das isotopias e a superposição das referências autonomiza a representação por si mesma. É uma certa voz do "sentimento" que se impõe, do sentimento como veia ou como estagnação sangüínea, como ar e como pedra, como arco e como tumba, como tombo e elevação. Sempre, em Blanchot, um desprendimento desfaz a pura narrativa (o que se poderia chamar, por contragolpe, a pura narratividade): oralização da narração em Au Moment Voulu (No Momento Desejado), fragmentação em L'Attente L'Oubli (A Espera o Esquecimento).

A força singular de Thomas L'Obscur (Thomas o obscuro) reside talvez nesta voz do sentimento, do sentir como viver e como morrer, como viver pelo morrer, como insurreição e como ressurreição, desconhecimento e reconhecimento, esta voz complexa do sentimento sem a qual "nós não somos jamais nós mesmos". E, ainda uma vez, esta força se emociona com a sensibilidade de um tocar, de um desvio, esta questão "pré-fenomenológica", escreve Derrida, na abertura de seu livro sobre Nancy, "a menos que se pudesse dizê-la também transfenomenal". Um livro no qual, relembrando ligeiramente, a única referência a Blanchot figura numa nota consagrada ao "tocável-intocável, sempre entre vida e morte, entre palavras e animais", a respeito de uma cena da leitura de Thomas L'Obscur (Thomas o obscuro). Como então manter a possibilidade de um sujeito, de um sentimento do sujeito, numa cena de reconhecimento da morte? Derrida insiste sobre a figura "da assombração espectral (fantasma)": "O fantasma com coração de (se) sentir? Então a assombração, entre vida e morte, ditaria um luto impossível, um luto sem fim, a vida mesma". É a "cena pouco visível deste luto" que Blanchot expõe, até a impossibilidade ou heterogeneidade ou desunião da imagem, entre medo do tocar e, como o formula Jean-Louis Giovannoni, ausência real: "Para nós que somos o lugar, a parede sensivel do que nos foi retirado para sempre: a ausência é talvez a única forma de presença que podemos realmente tocar, a única forma que podemos sentir no menor de nossos gestos; a única que pode nos restituir ao movimento da vida, privando-a em nós a todo momento".

A "assombração espectral" deixa uma cicatriz indelével. Mas é também sem esta cicatriz que nós não seríamos "nunca nós mesmos". Eu recordarei a anedota, a anedota-acontecimento relatada por Nancy, por ocasião da homenagem a Derrida, organizada pelo Collège International de Philosophie (Colégio Internacional de Filosofia), no dia 21 de outubro último. Durante a última entrevista entre os dois amigos, no hospital, no dia 8 de outubro, na véspera de sua morte, Derrida havia sorrido, alegando a sua nova cicatriz, tão longa, doravante, dizia, quanto a de Nancy.

Comemorar não consiste em multiplicar as homenagens plenas, banalizadas no idioma singular da lembrança. A homenagem não vai nunca sém o pesar nem, Blanchot e Derrida nos lembravam freqüentemente, a hospitalidade sem a inospitalidade, a discrição sem a indiscrição, o testemunho sem a ficção, o reconhecimento sem o desconhecimento, a ressurreição sem o esquecimento, a outra morte sem a minha. Neste sentido, as dezesseis remessas de Chaque Fois Unique (Cada vez único), o fim do mundo são todos orientados, magnetizados, polarizados pelo décimo - sétimo, o último, o inteiramente último, fora do livro, ocioso, aquele que Derrida não podia faltar de escrever por ele mesmo, estas poucas frases pronunciadas por Derrida, o filho mais velho, Pierre, diante da tumba aberta de Derrida, o pai, Jacques, diante da tumba no qual 
o caixão acabara de ser depositado. Uma tumba na qual "dúzias de mãos" terminaram por acolhê-lo, algumas frases que haviam sido precedidas por dezesseis homenagens, "sentimentos" que poderiam definitivamente se transmitir, desde "este aniquilamento pelo qual ele morrera sem permitir que se o acreditasse morto".

Far-se-ia necessário então ler e reler as palavras que Derrida, dezesseis vezes mais que uma, depositou na tumba dos mortos. Tomar a medida do imensurável tornara-se e ficará como uma postura que não será atribuída por ninguém além dele próprio. Ele nos "precedeu" e nos coloca numa postura da qual não terminamos de tomar a medida, já que ele nos abandona, "até o extremo", na "ambigüidade" de nossa vida e de nossa morte. Esta obrigação, esta responsabilidade, este dom, sem os quais nós não seríamos jamais "nós mesmos", Derrida não cessou de repetir até que ponto eles eram impossíveis de serem incorporados. À noção dialética do "trabalho do luto", ele opôs a obstinação de um "luto impossível que", eu o cito, "deixando ao outro sua alteridade, em respeito ao afastamento infinito, recusa ou se sente incapaz de tomá-lo em si, como na tumba ou a cova de um narcisismo". A tumba ou a cova do narcisismo só têm honra se se mantiverem entreabertas, e a vida se passa sem se cessar de medi-las. É porque consentir em falar dos mortos é tão impossível e necessário quanto recusá-lo. Far-se-ia necessário reler também, neste sentido, a forma ao mesmo tempo simultaneamente decisiva e incompleta do último texto que Derrida consagrou a Blanchot, no qual ele cita, quase que para concluir, aproximadamente quase o conjunto do capítulo de Thomas L'Obscur (Thomas o obscuro), do qual aqui evoquei um trecho. Ele o cita sem realmente o comentar, colocando-o sob o signo dos poderes da literatura, "quanto ao que a ficção literária ou a narração fantástica podem pôr em cena de indecisão ou de irresolúvel entre dois vivos". A última citação, ela, é introduzida como um exemplo e ficará para sempre sem comentário. Trata-se de uma passagem de Pas au-delà (Passo no além) evocando o Neutro, como "doce interdição do morrer" e alcance "na aproximação do longínquo". Estas últimas linhas de Derrida sobre Blanchot remete-nos à decisão que um comentário deve tentar traçar entre duas mortes. É segundo esta lei de nossos solos que poderíamos também recomeçar uma leitura dos textos de Derrida sobre Blanchot, estas duas frases como um arco sobre nossos ombros: "Jacques Derrida morreu", "Maurice Blanchot morreu". 